\title{
Potential Economic Growth of China based on Low Carbon Economy
}

\author{
Xiangnan Song \\ Xijing University, Xi'an, 710123, China \\ E-mail: 34616310@qq.com
}

\begin{abstract}
With the rapid development of China's economy sustainable development ideas and green economy idea were began to received more and more attention at the same time. Low carbon economy has become a focus of attention in economic growth pattern planning in the future. This requires the development of the economy, the pursuit of efficiency, not only to achieve a low carbon economy. This paper briefly introduces the basic concept of low carbon economy, discusses the important role of low carbon economy in promoting economic growth, and analyzes the potential economic growth of China under the constraints of low-carbon economy.
\end{abstract}

Keywords-Low carbon economy; potential economic growth; sustainable development

\section{INTRODUCTION}

The concept of low carbon economy is the first in 2003, the basic requirement is that the control of pollutant emissions, while the economic growth and the development of the local environment [1]. The emergence of low carbon economy concept is based on the current growing environmental problems. As the largest developing country in the world, China has been in the process of development, despite the gradual and steady growth in the economy, on the other hand, in the process of urbanization and industrialization, the environmental problems are more and more attention. Can be, in today's China is largely dependent on the environment for economic development, and this is actually a kind of scientific, unhealthy development. In addition, the total resources of our country is limited, the per capita resources occupy more in the world, which requires us to change the way of economic development in the future development activities, adhere to the low carbon economy development model, and realize the coordinated development between economic growth and resource environment [2-5].

\section{ONE BASIC CONNOTATION OF LOW CARBON ECONOMY}

The concept of "low carbon economy" was first appeared in government documents in 2003[6].

In 2003, the government promulgated the energy white paper, "the future of our energy: create a low-carbon economy", clearly pointed out that the development of low-carbon economy requires that it has its own time.At present, due to the energy crisis and climate change and other factors directly affect the economic development, through the use of low-carbon economic development model, the basic principles of sustainable development can be achieved through innovation, transformation, development and other means to maximize the control of high carbon energy consumption, reduce carbon emissions, so as to achieve a win-win social development and environmental protection[7]. Generally speaking, the development of low-carbon economy, the need to build on the following basis: first, the development of low-carbon economy, on the need for specific production, exchange, consumption process, to try to achieve low carbon economy, and strictly control the emissions of carbon dioxide. Secondly, the development of low-carbon economy, on the requirements of specific production, exchange, consumption process, the process of energy consumption must comply with the laws of ecology, to ensure the sustainable development of ecological economy.

\section{THE RELATIONSHIP BETWEEN LOW CARBON ECONOMY AND ECONOMIC GROWTH}

The relationship between low carbon economy and economic growth, including four aspects, namely, the realization of sustainable development, adjustment of industrial structure, the realization of economic development, the correct handling of economic growth, export trade, carbon emissions of the relationship between the three[8]. Specifically: First, the development of lowcarbon economy can effectively achieve the sustainable development of our country. Sustainable development is a long-term development of economic growth model, it refers to the process of human development, not only to meet the needs of contemporary people, but not to damage the needs of future generations, this is a kind of strategic ability to meet the present and future. Sustainable development is the basic requirement and important part of the scientific development view. It has an important role in guiding the development of the national economy and the people's livelihood. The low carbon economy is the embodiment of sustainable development in the economic development, through the effective use of the existing natural resources, in order to maintain good basic construction development requirements, reduce the damage to the unit environment, so as to maximize the utilization of resources. Second, the development of lowcarbon economy can adjust the industrial structure in time. At present, China is in the period of rapid development, and the process of industrialization and modernization is accelerating, the development plan and activities are more and more, and the corresponding resources demand also reached a new height of history. In the traditional economic development mode, the enterprise often uses the extensive development mode, which affects the speed and efficiency of economic development. On the other hand, it also plays a role in the effective utilization of resources. For this one problem, the optimization and upgrading of 
industrial structure become inevitable. The low carbon economy is based on the current industrial structure adjustment of the historical demand, which is the ultimate goal is to improve the utilization of resources. Third, the development of low-carbon economy is conducive to China's economic development by leaps and bounds. As the largest developing country in the world, China has changed greatly since the reform and opening up, but compared with the developed countries, the level of economic development of our country still needs to be strengthened. In the active participation in the international trade, we should not only reflect the development of its own characteristics, but also can not give the right to the economic development of the developed countries, the dominant ideology. And low carbon economy has become a very good and foreign countries continue to tighten the dialogue platform and media. Through the discussion with other developed countries, a series of problems about low carbon economy will help us to reflect on our own, and actively explore new economic development model, and ultimately achieve the country's leapfrog development. Three, to achieve the low carbon economy under the constraints of China's potential economic growth of specific measures[9]

\section{TO ACHIEVE THE LOW CARBON ECONOMY UNDER THE CONSTRAINTS OF CHINA'S POTENTIAL ECONOMIC GROWTH OF SPECIFIC MEASURES}

\section{A. the transformatilon of economic development mode}

In view of the current economic development mode is not adapted to the needs of the times development, in the development of China's economy, we should focus on the transformation of economic development mode, take full advantage of the opportunity to solve the problem of carbon emissions, carbon emissions". To achieve the development of emission reduction, it is required in the process of developing the economy, we must constantly improve the resource environment, and constantly adjust the export trade of product types and types, so as to achieve sustainable development of science. Need to explain is that in recent years, although the relevant professionals have been to improve energy efficiency, reduce carbon emissions and other aspects made an important attempt, but in fact China's energy-saving emission reduction effect is far less than some developed countries. This will prompt us to realize the low carbon economy, we should actively transform the economic development mode, optimize the industrial structure and energy consumption structure, realize the long-term, stable and sustainable development.

\section{B. the transformation of trade growth mode}

In view of the problems that the current trade growth mode is relatively backward, we should focus on changing the mode of trade growth, and realize the reform and development of the trade system. China's traditional trade growth mode is extensive growth mode. Due to the product production process, the product has not received strict and accurate control, which makes the resource intensive and pollution intensive products continue to emerge, and exacerbated by the export of primary products and cheap products. In the process of export processing, carbon emissions as a representative of the development of the problem, we want to explore as soon as possible the green trade growth model. Specifically, the change in trade growth mode can be from the following several aspects. First, we must focus on the adjustment of the export trade structure, which requires the state and the relevant departments to actively reduce resource intensive and pollution intensive products export quantity, control good export frequency. On the basis of the development of the healthy development, adjust the export structure, and set up a resource-saving and environment-friendly trade export structure as soon as possible, and secondly, to build a sound green trade policy system. Due to the low carbon economy in China, it has not formed a relatively complete and scientific trading system, so the lack of necessary guidance and regulation in the economic activities. To solve this problem, in the construction of green trade policy system, it should be the basic conditions of our country as the foothold, to learn foreign advanced experience, learn from each other, and gradually worked out a set of effective strategy for low carbon economic development. Adhere to the product as the fulcrum, the enterprise as the focus, to the industry as the main line, focus on building a green trade policy system including green investment policy, environmental tariff policy, market access system and other policies, and finally, to achieve a low-carbon economy can not simply rely on export trade, but also to focus on domestic demand. This requires that we should according to the current situation and the basic law of social development, focus on stimulating domestic demand, in order to achieve the purpose of promoting economic growth. To achieve a low carbon economy, the basic requirements for the current social development, to create a low carbon oriented to the mode of economic growth through both and export trade, and ultimately achieve the effect of trade to achieve emission reduction ". However, some points should be mentioned. First of all, due to the absence of official provincial capital stock and $\mathrm{CO} 2$ emissions data, we have to calculate values based on previous studies (Zhang,

2008; Du et al., 2012; Chang et al., 2013). Therefore, the data may cause biased estimation on the results[10], which is a common weakness of empirical studies. Furthermore, China's LCEE is only

compared among the Chinese provinces included in this study. If compared to other advanced countries (e.g., OECD countries), the efficiency values would have likely been much worse. Based on data availability, this study could also be conducted using the same method to find the LCEE ranks of China and other advanced countries in the future, which can help to further improve the LCEE of China. 


\section{Figures and Tables}

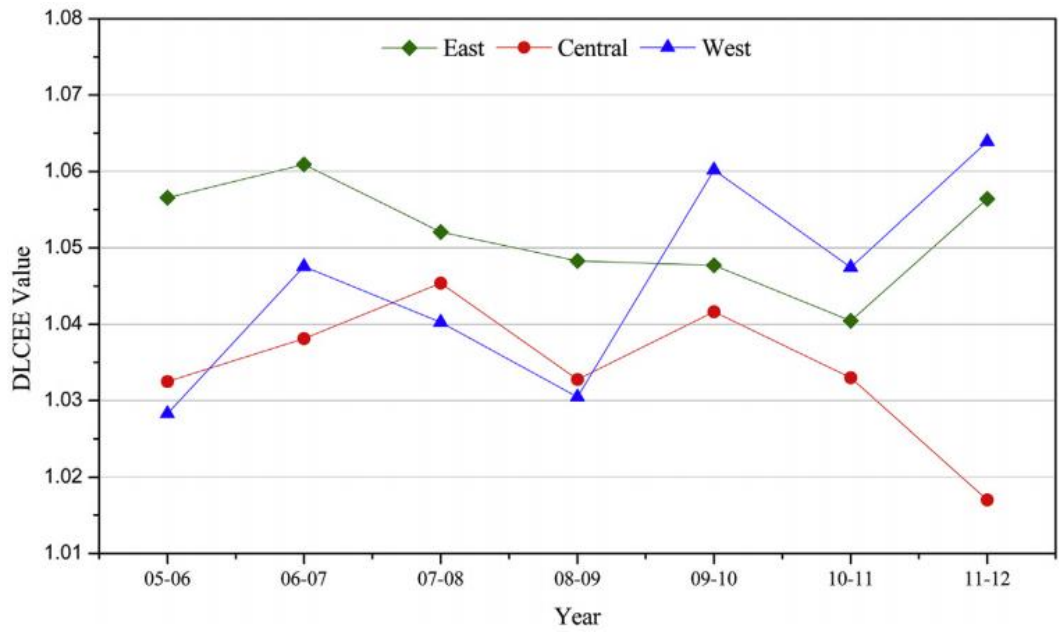

Figure 1. The average DLCEE values of different areas over time.

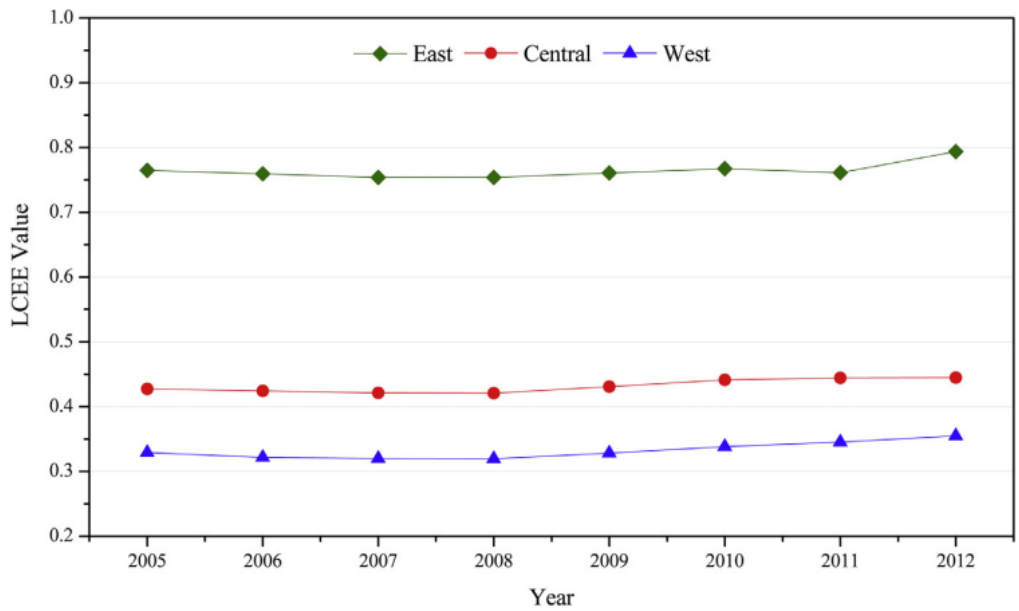

Figure 2. The average LCEE values of different regions over time.

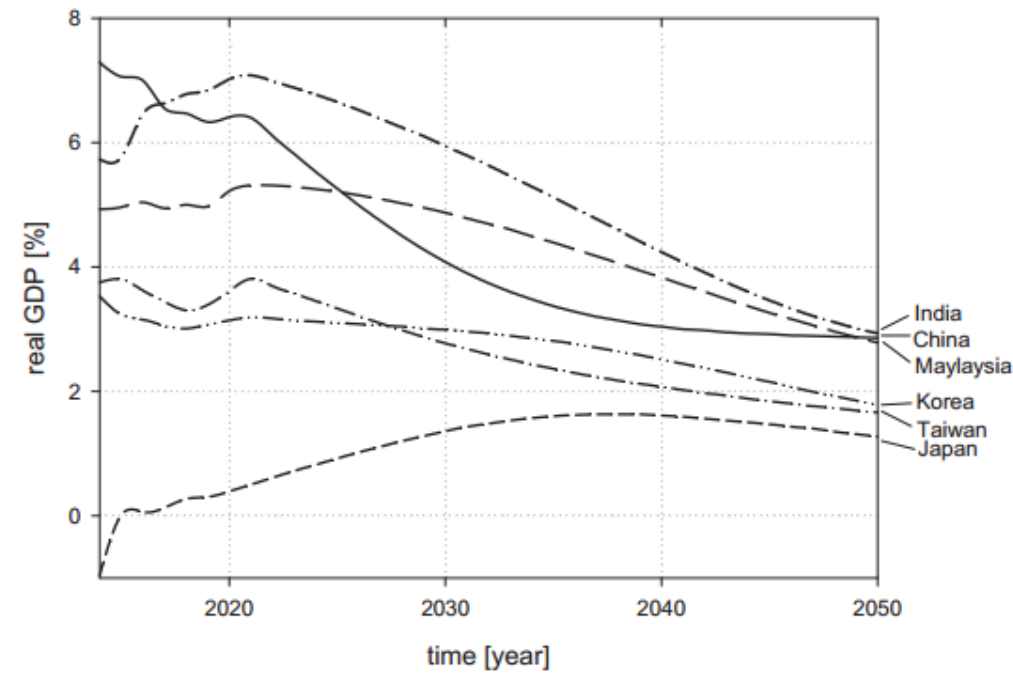

Figure 3. Baseline forecasting for real GDP growth rate (\%) to2050 


\section{CONCLUSIONS}

Since the reform and opening up, China has undergone earth shaking changes, which is reflected in the economic performance of the rapid economic development, comprehensive national strength increased, it can be said that China's economic change has won the world's attention. At the same time, in the process of rapid economic development, some problems are emerging, including low investment efficiency, investment ratio, serious waste of resources, serious environmental pollution and other issues, these problems are not resolved in time, will cause immeasurable impact on the development of China's economy. In the face of this grim implementation, the innovation and development of economic growth mode has become the inevitable, while the low carbon economy is a very good idea and topic for economic growth mode. If the low carbon economy, if the current resource pricing is too low and other issues to explore solutions, how to correctly deal with the relationship between economic growth, export trade, carbon emissions, has become an important topic of sustainable development in the current. We only have to explore the scientific and effective way to achieve the harmonious unity between man and nature.

\section{REFERENCES}

[1] Zhou Shaopeng. The need to handle several relations of economic growth $[\mathrm{J}]$. China industrial economy, 2010, (01): 112-113

[2] Mao Yan. Asia will become the world's fastest growing region [J]. International Economic Cooperation

[3] As, 2012,3 (06):78-79.

[4] he Liping.20 century economic growth and modernization of the experience of the development of [J]. international economic review, 2010,10 (21):63-64.

[5] sun.1978 - 1995 China economic growth leading factor empirical analysis of [J]. 2013,1 North trade, (02): 51-52.

[6] Zhou Shaopeng. The need to handle several relations [J]. China business administration research, 2013,2 (04): 166-167.

[7] Alcantara, V., Duro, J.A., 2004. Inequality of energy intensities across OECD countries: a note. Energ. Policy 32 (11), 1257e1260.

[8] Berk, I., Yetkiner, H., 2014. Energy prices and economic growth in the long run:

[9] theory and evidence. Renew. Sust. Energ. Rev. 36, 228e235.

[10] Bian, Y.W., Liang, N.N., Xu, H., 2015. Efficiency evaluation of Chinese regional industrial systems with undesirable factors using a two-stage slacks-basedmeasure approach. J. $\begin{array}{llrl}\text { Clean. } & \text { Prod. } & 87, & 348 \mathrm{e} 356\end{array}$ 